\title{
A
}

Acta HealthMedica

Volume 3, Issue 1, February 2018, Pages: 249, DOI: http://dx.doi.org/10.19082/ah249

\section{MORPHOLOGICAL AND CYTOSKELETON RENAL DAMAGE CAUSED BY ANDROCTONUS AUSTRALIS HECTOR VENOM}

\author{
Nesrine Issaad ${ }^{1}$, Aouatef Ait-Lounis ${ }^{2}$, Fatima Laraba-Djebari ${ }^{3}$
}

$1 \mathrm{PhD}$ student in Biochemistry-Immunology and Innovative Biotherapies, Department of Cellular and Molecular Biology, University of Sciences and Technology Houari Boumediene, Algiers, Algeria

2Assistant professor, Department of Cellular and Molecular Biology, University of Sciences and Technology Houari Boumediene, Algiers, Algeria

3Professor, Department of Cellular and Molecular Biology, University of Sciences and Technology Houari Boumediene, Algiers, Algeria

flaraba@hotmail.com

\section{TYPE OF ARTICLE: CONFERENCE ABSTRACT}

\begin{abstract}
Background: Androctonus australis hector venom (Aah) is a complex mixture that exhibits a wide range of biological properties and actions. The aim of the study is to investigate the effect of the Aah venom on the actin cytoskeleton in renal tissue.

Methods: Adult NMRI mice were injected with Aah venom $(10 \mu \mathrm{g} / 20 \mathrm{~g})$ or saline solution (control). Renal function was evaluated in sera $30 \mathrm{~min}$ and 24 hours after envenomation. Morphometric study was performed to quantify histopathological damage by measuring the area of each Bowman's capsule and the corresponding glomerular tuft. The actin cytoskeleton was detected by using rhodamine-conjugated phalloidin.

Results: Results showed an increase in creatinine levels (an indicator of altered glomerular filtration), urea, uric acid, ammonia and ions $(\mathrm{Na}+, \mathrm{Ca} 2+$ and $\mathrm{P})$. However, the potassium level decreased in renal tissue of envenomed mice. These results are correlated with the disorganization of the renal cortex and the increase in the area of the capsular space after envenomation. This increase was related to the distension of Bowman's capsule rather than a decrease in glomerular diameter and was observed after envenomation. Aah venom caused unbalanced redox status and important alterations in the cytoskeleton characterized by the redistribution of $\mathrm{F}$-actin in renal glomeruli and distal tubules.

Conclusion: The Aah venom induces renal cytoskeleton damage associated to functional renal alterations. This study could lead to the identification of the specific mode of actions of crude venom which cause the renal toxicity observed in patients and confirmed in animal models.
\end{abstract}

KEYWORDS: Aah venom, Cytoskeleton, F-actin, Renal function, Renal morphology.

\footnotetext{
Abstracts of Second International Conference on Health Sciences and Medical Technologies, 10-12 October 2017, Tlemcen, Algeria (ICHSMT-17)

(C) 2018 The Authors. This is an open access article under the terms of the Creative Commons Attribution-NonCommercialNoDerivs License, which permits use and distribution in any medium, provided the original work is properly cited, the use is non-commercial and no modifications or adaptations are made.
} 